
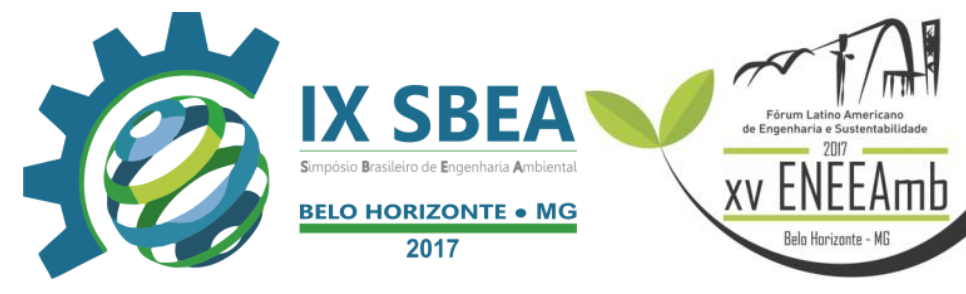

ÁREA TEMÁTICA: RECURSOS HÍDRICOS.

\title{
AVALIAÇÃO DA QUANTIDADE DE FÓSFORO TOTAL NO CÓRREGO DO VEADO EM PRESIDENTE PRUDENTE - SÃO PAULO.
}

Arthur Pereira dos Santos - arthursantos_10@ hotmail.com

Universidade do Oeste Paulista - UNOESTE

Elson Mendonça Felici - elson@ unoeste.br

Universidade do Oeste Paulista - UNOESTE

Mateus Ederli - mat3us_123@hotmail.com

Universidade do Oeste Paulista - UNOESTE

Paulo Barbosa Saqueti - paulo_saqueti@hotmail.com

Universidade do Oeste Paulista - UNOESTE

Daniel Ângelo Macena - daniel@ unoeste.br

Universidade do Oeste Paulista - UNOESTE 


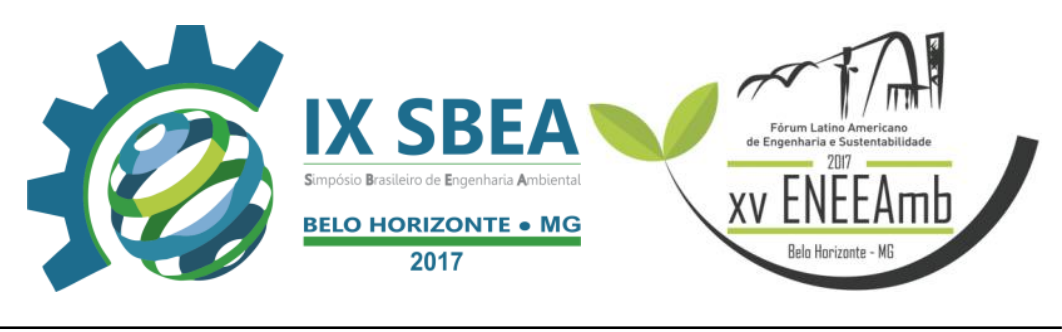

\section{RESUMO}

O presente artigo apresenta a análise de fósforo total das águas na bacia do córrego do Veado, afluente do rio Santo Anastácio, aonde os recursos hídricos superficiais vêm historicamente sendo degradados e contaminados por atividades diversas desenvolvidas na cidade de Presidente Prudente. Desta forma, objetiva-se analisar a qualidade das águas da bacia do córrego do Veado em relação ao parâmetro fósforo total. Por meio de análises realizadas em laboratório, durante 3 coletas, identificou-se que todos os pontos obtiveram resultados fora dos padrões estabelecidos na Resolução nº. 357/2005 do CONAMA, o que pode estar acontecendo devido a fatores como lançamento de efluentes tanto domésticos como industriais.

Palavras-chave: Lançamentos de Efluentes, Contaminação, Recursos Hídricos.

\section{INTRODUÇÃO/OBJETIVO}

Atualmente a humanidade sofre com um grande problema que afeta todo o planeta Terra: a poluição. Dentre esses tipos de poluição se encaixa a poluição hídrica, que ocorre principalmente pelo crescimento da população e a presença de inúmeras fábricas e indústrias em meio urbano, com o descarte de efluentes compostos por produtos químicos que alteram as propriedades da água. Apesar de ser um problema bastante comum e que tem tomado importância nos últimos tempos, o pólo regional do oeste paulista Presidente Prudente - está sujeita a sofrer com esse impacto ambiental devido a seu crescimento desordenado e sem planejamento.

O monitoramento da qualidade da água consiste em uma importante ferramenta que permite investigar, descrever e interpretar dados sobre a real situação da qualidade dos recursos hídricos, permitindo fomentar ações no sentido de se restabelecer as condições de equilíbrio e sustentabilidade destes ecossistemas impactados (JUNIOR, ARAÚJO, SOUZA, 2011, p.11).

As principais causas de ameaças à qualidade ambiental em uma bacia hidrográfica estão relacionadas às atividades não sustentáveis, com fins de lucro imediato, que não computam os custos ambientais e sociais, repassando-os a terceiro (PIRES, SANTOS \& DEL PRETTE, 2002). 


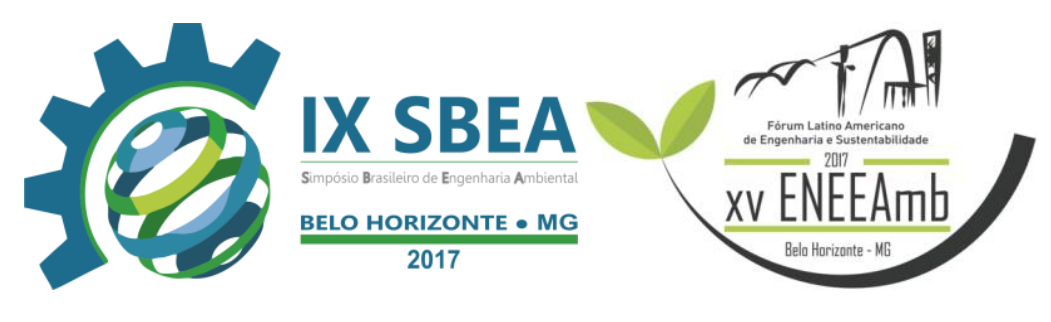

Tudo o que ocorre na bacia hidrográfica repercute direta ou indiretamente nos rios e na qualidade e quantidade das águas (LEAL, 1995).

De forma genérica, a poluição das águas decorre da adição de substâncias ou de formas de energia que, diretamente ou indiretamente, alterem as características físicas, químicas e biológicas do corpo d'água, de uma maneira que prejudique a utilização das suas águas para usos benéficos.

Segundo Sperling (2005), o fósforo é encontrado em corpos d'água em sua forma natural e na sua forma antropogênica, sendo a sua forma natural devido à dissolução de compostos do solo e a decomposição da matéria orgânica. A sua origem antropogênica é devido aos despejos domésticos, industriais, detergentes e excrementos de animais, além do uso de fertilizantes.

Diante do exposto, o objetivo deste trabalho é analisar a quantidade de fósforo total em diferentes pontos do córrego do Veado, visando saber a real condição que se encontra o corpo d'água, além de: a) verificar o atendimento e enquadramento aos padrões de qualidade da água constante na Resolução nº 357/2005, do Conselho Nacional do Meio Ambiente (CONAMA) e; b) determinar o ponto ou trecho crítico de poluição hídrica.

\section{METODOLOGIA}

Foram coletadas amostras de água em nove pontos distintos da bacia em estudo, em lugares estratégicos, sempre no leito principal do córrego, próximo a indústrias, afluentes, próximo a foz e o mais possível próximo a nascente, como ilustra a Figura 1.

O ponto de coleta 1 está localizado no Parque do Povo de Presidente Prudente. É o primeiro local a jusante da nascente do córrego, que não se encontra totalmente em canal fechado e por isso foi possível coletar amostras. O ponto de coleta 2 está localizado onde o córrego não está mais em canal fechado e fica próximo ao estacionamento de um shopping center. O ponto de coleta 3 está localizado abaixo da ponte da avenida Salim Farah Maluf e próximo ao maior shopping center da cidade. O ponto de coleta 4 está localizado atrás de alguns empreendimentos comerciais voltados para a avenida Manoel Goulart. O ponto de coleta 5 está localizado próximo a um frigorífico. O ponto de coleta 6 está localizado próximo ao bairro Jardim São Gabriel e o ponto 7 nas proximidades do 


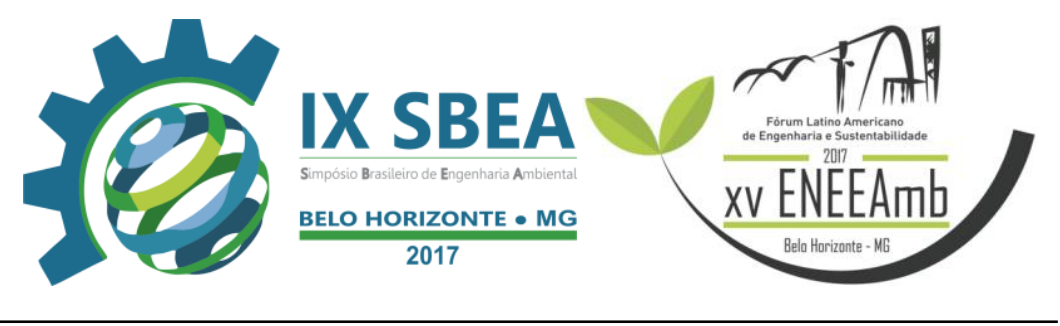

bairro Jardim Jequitibás. No ponto de coleta 8 o córrego já está em seu leito natural e não se encontra mais canalizado, e o ponto de coleta 9 está localizado próximo a foz do córrego do Veado, poucos metros antes de desaguar no córrego do Limoeiro.

Essas amostras foram submetidas a análises laboratoriais que revelaram a quantidade de fósforo total encontrado nos pontos coletados. Na Tabela 1 estão dispostas as coordenadas geográficas de cada ponto de coleta.

Tabela 1: Coordenadas geográficas dos pontos de coleta.

\begin{tabular}{|c|c|}
\hline Pontos & Coordenadas Geográficas \\
\hline Ponto 1 & $22^{\circ} 07^{\prime} 46^{\prime \prime} \mathrm{S}, 51^{\circ} 23^{\prime} 58^{\prime \prime} \mathrm{W}$ \\
\hline Ponto 2 & $22^{\circ} 06^{\prime} 54^{\prime \prime} \mathrm{S}, 51^{\circ} 24^{\prime} 29^{\prime \prime} \mathrm{W}$ \\
\hline Ponto 3 & $22^{\circ} 06^{\prime} 54^{\prime \prime} \mathrm{S}, 51^{\circ} 24^{\prime} 38^{\prime \prime} \mathrm{W}$ \\
\hline Ponto 4 & $22^{\circ} 07^{\prime} 03^{\prime \prime} \mathrm{S}, 51^{\circ} 25^{\prime} 00^{\prime \prime} \mathrm{W}$ \\
\hline Ponto 5 & $22^{\circ} 07^{\prime} 02^{\prime \prime} \mathrm{S}, 51^{\circ} 25^{\prime} 23^{\prime \prime} \mathrm{W}$ \\
\hline Ponto 6 & $22^{\circ} 06^{\prime} 59^{\prime \prime} \mathrm{S}, 51^{\circ} 25^{\prime} 34^{\prime \prime} \mathrm{W}$ \\
\hline Ponto 7 & $22^{\circ} 07^{\prime} 01^{\prime \prime} \mathrm{S}, 51^{\circ} 25^{\prime} 59^{\prime \prime} \mathrm{W}$ \\
\hline Ponto 8 & $22^{\circ} 06^{\prime} 51^{\prime \prime} \mathrm{S}, 51^{\circ} 26^{\prime} 21^{\prime \prime} \mathrm{W}$ \\
\hline Ponto 9 & $22^{\circ} 06^{\prime} 46^{\prime \prime} \mathrm{S}, 51^{\circ} 26^{\prime} 45^{\prime \prime} \mathrm{W}$ \\
\hline
\end{tabular}

Fonte: Os autores (2016). 

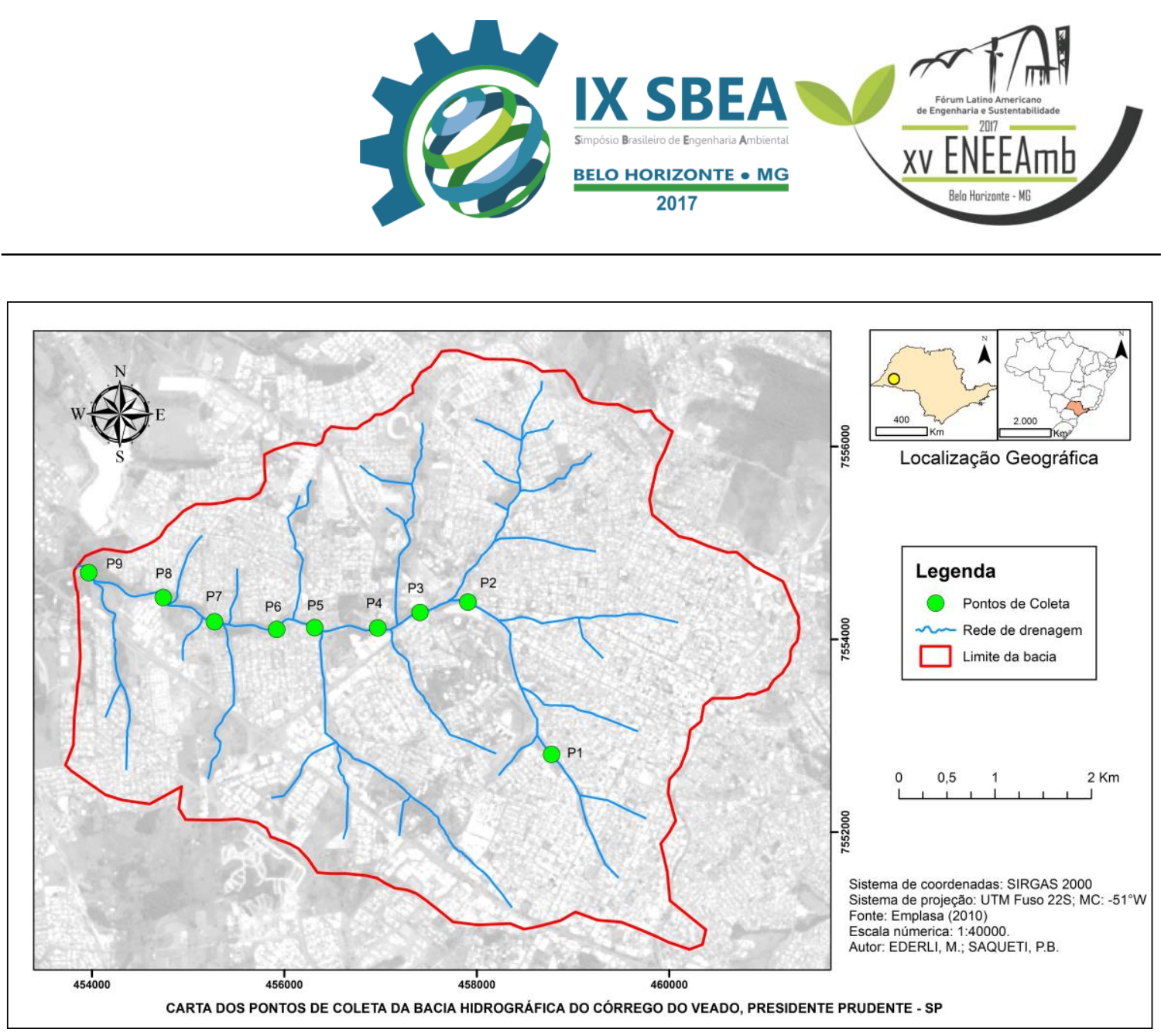

Figura 1: Pontos de coleta na bacia do córrego do Veado.

A bacia em questão vem historicamente sendo degradada e contaminada por atividades desenvolvidas na cidade de Presidente Prudente. Em consequência desses fatos, através do Decreto Estadual No 10.755 - de 22 de novembro de 1977, foi definido o córrego do Veado como classe 4. Além disso, o reservatório da bacia que o mesmo se encontra é responsável por abastecer 30\% de Presidente Prudente.

Coletaram-se as amostras nos dias 17/05/2016, 01/09/2016 e 22/09/2016, e foram realizadas análises de fósforo total no Laboratório de Qualidade da Água no Campus II da Universidade do Oeste Paulista (UNOESTE) e o método utilizado para análise foi o de redução com ácido ascórbico.

\section{RESULTADOS E DISCUSSÃO}

Os resultados das análises podem ser verificados na Tabela 2. 


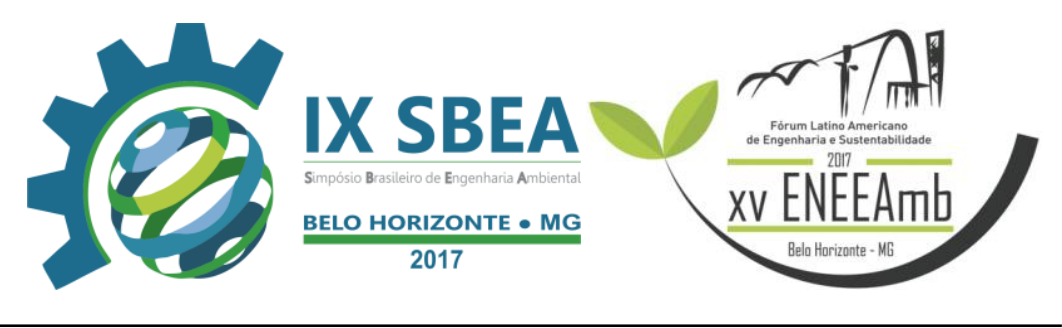

Tabela 2: Resultado da análise de fósforo total.

\begin{tabular}{c|c|c|c|c}
\hline \multirow{2}{*}{ Pontos } & \multicolumn{4}{|c}{ Fósforo Total (mg/L) } \\
\cline { 2 - 5 } & Coleta 1 & Coleta 2 & Coleta 3 & Média \\
\hline 1 & 8,16 & 8,76 & 6,27 & 7,73 \\
\hline 2 & 6,87 & 1,50 & 1,55 & 3,30 \\
\hline 3 & 7,73 & 3,46 & 1,16 & 4,11 \\
\hline 4 & 6,70 & 0,28 & 0,43 & 2,47 \\
\hline 5 & 11,08 & 1,20 & 2,23 & 4,81 \\
\hline 6 & 6,96 & 0,61 & 2,58 & 3,38 \\
\hline 7 & 7,13 & 1,24 & 1,20 & 3,19 \\
\hline 8 & 0,82 & 0,42 & 0,34 & 0,52 \\
\hline 9 & 0,62 & 0,34 & 0,38 & 0,44 \\
\hline
\end{tabular}

Fonte: Os autores (2016).

A partir dos resultados é possível observar que todas as coletas em todos os pontos estão fora dos padrões estabelecidos para classe 1,2 ou 3, pois todos os resultados estiveram acima de $0,15 \mathrm{mg} / \mathrm{L}$, corroborando a classificação do Decreto Estadual $\mathrm{n}^{\circ}$ 10755 de 22 de novembro de 1977 como corpo d'água classe 4.

Destaca-se o primeiro ponto de coleta como o ponto crítico da bacia: todos os resultados apresentaram valores muito altos, o que pode estar associado aos lançamentos clandestinos de esgoto doméstico, mas de difícil identificação da contribuição, levando em consideração que o ponto se encontra canalizado em canal fechado e a coleta foi realizada no primeiro local sem canalização a jusante da nascente do córrego. Outra possibilidade é que esses valores possam estar associados aos excrementos de animais pelo fato do ponto estar localizado no Parque do Povo - ponto turístico da cidade - onde há uma grande circulação de pessoas com animais de estimação.

Os pontos 5, 6 e 7 também apresentaram altos índices de fósforo na água. Acredita-se que esse motivo esteja relacionado ao lançamento de efluentes no córrego, que pode ser verificado nas proximidades do ponto 5 e está apresentado na Figura 2. 

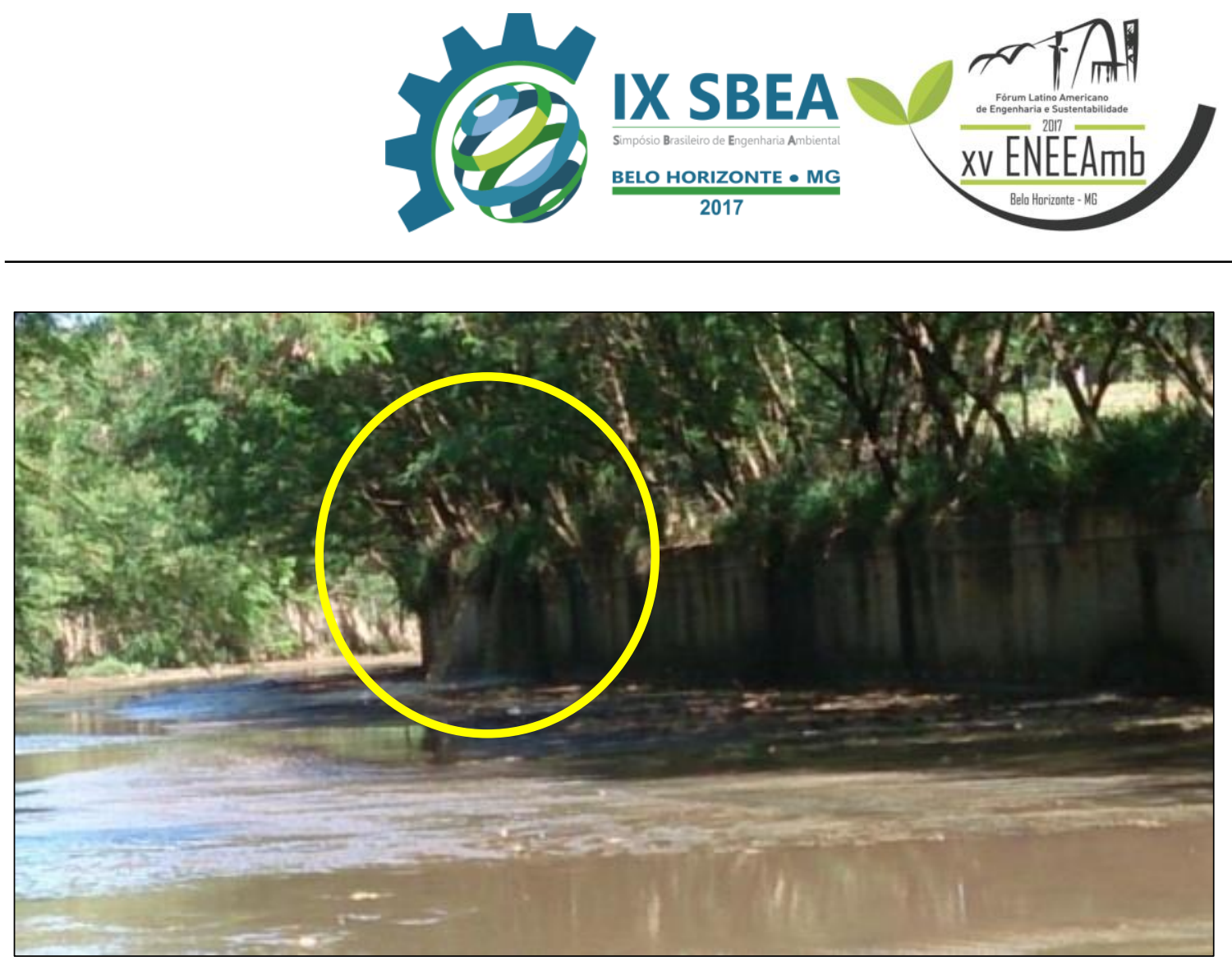

Figura 2: Lançamento de efluentes no Córrego do Veado.

Fonte: Os autores (2016).

Os pontos oito e nove possuem os menores valores de fósforo total pois já se encontram em leito natural, com uma maior vazão devido ao acréscimo de seus afluentes, possibilitando a maior diluição do parâmetro, além da ocorrência da autodepuração no córrego.

\section{CONCLUSÕES/RECOMENDAÇÕES}

Em relação ao monitoramento da qualidade das águas e das coletas e análise, os nove pontos amostrados e analisados evidenciaram através dos altos valores de fósforo total encontrados, má qualidade da água do córrego do Veado. Além disso, é fato comum em todos os estados do Brasil a falta de fiscalização em corpos hídricos que atravessam malhas urbanas. Partindo do pressuposto que, se tratando de corpos hídricos eutrofizados e lançamento de efluentes clandestinos, a fiscalização falha com a realização de medidas corretivas a partir da consequência, e a causa do impacto acaba sendo esquecida pela lei.

Em relação ao enquadramento dos corpos d'água de acordo com a Resolução $n^{\circ}$. 357/2005 do CONAMA, considerando apenas o parâmetro fósforo, todos os pontos estariam enquadrados como Classe 4, confirmando assim a classificação prevista pelo Decreto Estadual no 10.755 . 


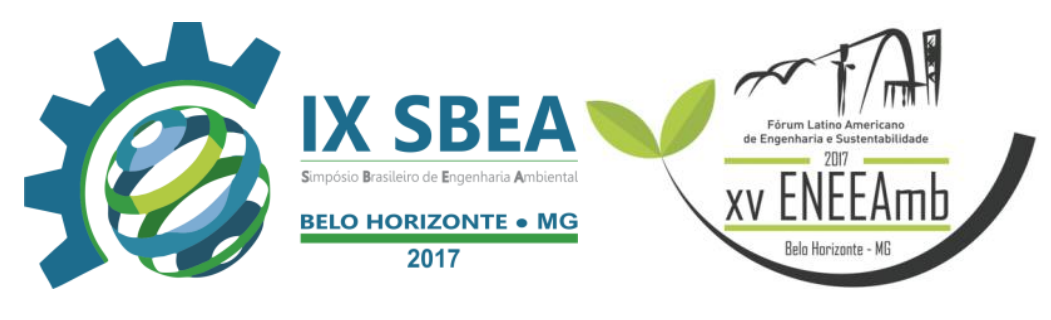

Diante de todos os resultados obtidos e observações realizadas, os pesquisadores sugerem as seguintes recomendações:

- estudo minucioso da capacidade de autodepuração de outros componentes químicos neste córrego; e

- tratamento do efluente antes do lançamento, e, adjunto à isso, maior fiscalização por parte das entidades responsáveis, como a CETESB, prefeitura, Ministério Público, etc.;

\section{REFERÊNCIAS BIBLIOGRÁFICAS}

BRASIL. Resolução CONAMA 357, de 2005. Ministério do Meio Ambiente.

CETESB - Secretaria do Meio Ambiente. Companhia de Tecnologia de Saneamento Ambiental. Relatório de qualidade das águas interiores do estado de São Paulo 2012/CETESB. São Paulo: 2013.

LEAL, A.C. Meio ambiente e urbanização na microbacia do Areia Branca Campinas/SP, Rio Claro, 155 p., 1995. Dissertação (Mestrado) - Universidade Estadual Paulista.

JUNIOR, P. P. A.; ARAÚJO, R. R.; SOUZA, A. Monitoramento da qualidade da água no manancial do rio Santo Anastácio, Colloquium Exactarum, Presidente Prudente, v. 3 , n. 1,2011.

PIRES, J. S. R; SANTOS, J. E; DEL PRETTE, M. E. A Utilização do Conceito de Bacia Hidrográfica para a Conservação dos Recursos Naturais. Uso de Conceitos de Bacias Hidrográficas. 2002.

SPERLING, Marcos Von. Introdução à qualidade das águas e ao tratamento de esgotos. $3^{\text {a }}$ Edição. Princípios do tratamento biológico de águas residuárias. Editora da Universidade Federal de Minas Gerais - UFMG - Belo Horizonte, 2005. 